CLINICAL STUDY

\title{
Active acromegaly is associated with decreased hs-CRP and NT-proBNP serum levels: insights from the Belgian registry of acromegaly
}

\author{
Johan Verhelst, Brigitte Velkeniers ${ }^{1}$, Dominique Maiter ${ }^{3}$, Patrick Haentjens ${ }^{2}$, Guy T’Sjoen ${ }^{4}$, Ernst Rietzschel ${ }^{5}$, \\ Bernard Corvilain ${ }^{6}$, Pascale Abrams ${ }^{7}$, Frank Nobels ${ }^{8}$, Roger Abs ${ }^{9}$ and Marie Bex ${ }^{10}$ \\ Department of Endocrinology, ZNA Middelheim, Lindendreef 1, B-2020 Antwerp, Belgium, ${ }^{1}$ Department of Endocrinology and ${ }^{2}$ Center for Outcomes \\ Research and Laboratory for Experimental Surgery, Universitair Ziekenhuis Brussel, Vrije Universiteit Brussel, B-1090 Brussels, Belgium, ${ }^{3}$ Department \\ of Endocrinology, St Luc University Hospital, Université Catholique de Louvain, B-1200 Brussels, Belgium, Departments of ${ }^{4}$ Endocrinology and \\ ${ }^{5}$ Cardiology, Ghent University Hospital, B-9000 Gent, Belgium, ${ }^{6}$ Department of Endocrinology, Erasme University Hospital, Free University of Brussels, \\ Campus Erasme, B-1070 Brussels, Belgium, ${ }^{7}$ Department of Endocrinology, St Augustinus Hospital, B-2610 Wilrijk, Belgium, ${ }^{8}$ Department of \\ Endocrinology, OLVE, B-9300 Aalst, Belgium, ${ }^{9}$ Antwerp Centre for Endocrinology, B-2600 Berchem, Belgium and ${ }^{10}$ Department of Endocrinology, \\ University Hospitals Leuven, B-3000 Leuven, Belgium \\ (Correspondence should be addressed to J Verhelst; Email: johan.verhelst@zna.be)
}

\begin{abstract}
Objective: Patients with active acromegaly have an increased prevalence of cardiomyopathy and heart failure but a less than expected risk of coronary artery disease, considering the frequent association of diabetes mellitus and hypertension. We examined whether changes in high-sensitive C-reactive protein (hs-CRP) and N-terminal pro-brain natriuretic peptide (NT-proBNP) might contribute to this phenomenon.

Design and methods: Two hundred patients of the Belgian acromegaly registry (AcroBel) were divided in two groups: active disease (IGF1 Z-score $>2 ; n=95$ ) and controlled disease (IGF1 Z-score $\leq 2$; $n=105)$. Serum levels of hs-CRP and NT-proBNP were measured and correlated with BMI, blood pressure, fasting lipids, fasting glucose and insulin, HbA1c, IGF1, interleukin 6 (IL6), adiponectin, and sE-selectin. In a subset of acromegaly patients, hs-CRP, IL6, and NT-proBNP levels were also compared with those/the values of an age-, gender-, and BMI-matched reference group.

Results: Patients with active acromegaly had significantly lower levels of hs-CRP (median (interquartile range), $0.5 \mathrm{mg} / \mathrm{l}(0.1,0.9) \mathrm{vs} 1.3 \mathrm{mg} / \mathrm{l}(0.5,4.1) ; P<0.001)$ and NT-proBNP, $(47.0 \mathrm{ng} / \mathrm{l}(26.0,86.0)$ vs $71.0 \mathrm{ng} / \mathrm{l}(43.0,184.0) ; \mathrm{P}<0.001)$ compared with patients with controlled acromegaly. Compared with the reference population, hs-CRP was not different in controlled acromegaly but significantly lower in active acromegaly (median, $0.4 \mathrm{mg} / \mathrm{l}(0.1,0.8) \mathrm{vs} 1.4 \mathrm{mg} / \mathrm{l}(0.8,2.9) ; P<0.001)$, while NT-proBNP was similar in active acromegaly but significantly higher in controlled acromegaly (66.5 ng/l (40.0, 119.5) vs $50.8 \mathrm{ng} / \mathrm{l}(26.5,79.7) ; \mathrm{P}<0.001)$.

Conclusions: Patients with active acromegaly have significantly lower values of NT-proBNP and hs-CRP compared with patients with controlled disease and even lower values of hs-CRP compared with control subjects.
\end{abstract}

European Journal of Endocrinology 168 177-184

\section{Introduction}

Active acromegaly is associated with increased morbidity and mortality $(1,2)$. Among the causes of death, cardio- and cerebrovascular events are particularly prominent (3). The causal relationship between chronic excess in GH and insulin-like growth factor 1 (IGF1) and cardiovascular morbidity seems to be multifactorial and includes hypertension, cardiomyopathy, and direct vascular alterations such as vascular stiffness (4). Acromegalic cardiomyopathy is variably characterized by concentric cardiac hypertrophy associated with diastolic dysfunction, abnormalities of cardiac rhythm, and/or alterations of cardiac valves (5). In later stages, impaired systolic function evolving to heart failure may occur. In contrast, no increased prevalence of coronary artery disease was found in patients with newly diagnosed acromegaly $(6,7)$. Similarly, the extent of carotid atherosclerosis and carotic internal media thickening in acromegalic patients was not higher than that in non-acromegalic subjects $(6,8)$. The reasons for this unexpected observation are still unclear, but this finding suggests that the known atherogenic effects of hypertension, insulin resistance, and diabetes induced by $\mathrm{GH}$ excess (9) are counterbalanced by cardioprotective factors (7). 
Several biomarkers have now been identified to be associated with atherosclerotic morbidity and are used in clinical practice to determine individual cardiovascular risk and treatment strategy. Two such markers are the inflammatory protein high-sensitive C-reactive protein (hs-CRP), which is related to cardiovascular disease and is stimulated by the proinflammatory cytokine interleukin 6 (IL6) (10), and the N-terminal pro-brain natriuretic peptide (NT-proBNP), used as a diagnostic parameter for congestive heart failure (11). Previous studies on patients with active acromegaly have shown lower than normal values of hs-CRP in most $(9,12,13,14,15)$, but not all studies (16). Data on NT-proBNP are contradictory, since values were found to be either lower in active acromegaly $(13,17)$ or not influenced by the acromegaly status $(16,18)$.

To further characterize the cardiovascular risk factor profile in acromegaly, we measured in this study hs-CRP and NT-proBNP in a large cohort of patients with controlled and uncontrolled disease. We also compared these data with those obtained from a reference population.

\section{Materials and methods}

\section{Overall design}

To address our research questions we used two distinct methodological approaches. First, we analyzed clinical and biochemical characteristics of patients who had been included in the Belgian acromegaly registry (crosssectional design). Next, we compared a subset of these acromegaly patients with a group of age- and gendermatched healthy controls from the general population (matched case-control design).

\section{Acromegaly patients}

Patients were selected from a nationwide survey in Belgium and the Grand Duchy of Luxembourg in 2003-2004 (AcroBel-1), which included patients with acromegaly diagnosed or in follow-up since January 1, 2000. The survey design and the main demographic, epidemiological, and outcome results have been reported previously (19).

Of the 316 patients with centralized measurements of GH (mean of three samples) and IGF1 (St Luc University Hospital, Brussels, Belgium), 205 had simultaneously local determinations of fasting glucose, HbAlc, and lipids, and additional measurements of fasting insulin, hs-CRP, NT-proBNP, IL6, adiponectin, and sE-selectin performed in another central laboratory (University Hospital, Antwerp, Belgium).

We excluded patients with GH deficiency $(n=5)$ on the basis of their disease status reported by the referring physician and a low-IGF1 Z-score for age and gender, leaving 200 patients for analysis. In insulin-treated patients $(n=3)$, data on insulin levels were discarded.

\section{Healthy controls}

The 200 acromegaly patients were individually matched for age (within 2 years), gender, and BMI (within $0.5 \mathrm{~kg} / \mathrm{m}^{2}$ ) with a control group of healthy Belgian individuals from the Asklepios study (20). This reference group is a representative cohort of 2524 communitydwelling male and female volunteers, aged $35-55$ years at study initiation (October 2002) and recruited from the twinned communities Erpe-Mere and Nieuwerkerken near Brussels, Belgium. We conducted a 1:2 matching in which one acromegaly patient (case) had two matching controls. Fifty-one patients could not be matched because of a too large discrepancy in age and BMI (both higher in acromegaly). Of the 149 remaining acromegaly patients, 148 cases had two matching controls and one case had only one matching control from the Asklepios study.

\section{Assays}

Glucose, HbA1c, and lipids were measured locally by standard techniques. Serum GH and IGF1 concentrations were measured by chemiluminescence immunoassays (Nichols Advantage HGH assay and Nichols Advantage IGF1 assay; Nichols Institute Diagnostics, San Juan Capistrano, CA, USA). At the time of measurement (December 2004), GH values were still expressed in terms of the first WHO international standard 80/505 for pituitary-derived GH. The conversion factor for expression of $\mathrm{GH}$ concentration in terms of the new WHO international standard 98/574 is 0.56 (19). IGF1 values were compared with age- and genderspecific normal values and were expressed as a Z-score (normal range -2 to +2 ).

In the patients with acromegaly, IL6, adiponectin, and sE-selectin were measured by quantitative sandwich immunoassays (Quantikine HS; R\&D Systems, Minneapolis, MN, USA). hS-CRP was measured by an immunoturbidimetric method (BN II analyzer; Dade Behring, Glasgow, UK). Insulin was measured by electrochemiluminescence immunoassay (Elecsys 2010; Roche Diagnostics).

In the control persons, IL6 was measured by chemiluminescent sequential immunometric assay (Immulite 2000; Diagnostic Products Corporation, Los Angeles, CA, USA) and hs-CRP was measured by a immunoturbidimetric method (Integra 400 analyzer; Roche Diagnostics). NT-proBNP, in both patients and controls, was determined with the same sandwich immunoassay (Elecsys 2010; Roche Diagnostics).

\section{Definitions}

Active acromegaly was defined as an IGF1 Z-score $>2$, whereas patients with an IGF1 Z-score between -2 and +2 were considered as having controlled disease. In accordance with earlier findings, IGF1 was considered the determining parameter for disease activity in patients with discordant IGF1 and GH values (21). 


\section{Statistical analysis}

Acromegaly patients For each group of interest categorical data are presented as percentages and continuous data as mean \pm s.D. or by the median (interquartile range (IQR)) in case of non-normal distribution, or graphically as boxplots. Comparisons between groups were performed by $\chi^{2}$ tests for categorical variables and by Student's $t$-test for continuous variables based on log-transformed data. Because of baseline differences in gender and duration of disease between both groups, multivariate regression analysis was done with adjusting for age, gender, and duration of disease to further assess between-group differences for continuous variables. For the risk factors of primary interest in the current report (hs-CRP, IL6, and NT-proBNP), additional multivariate regression analyses further adjusting for the presence of TSH and ACTH deficiency were also performed. Likewise, multivariate regression analyses were conducted to assess the contribution of the presence of diabetes, arterial hypertension, and cardiac disease in relation to the measured parameters. Correlations between continuous variables were quantified by the Pearson's correlation coefficient using log-transformed data. Partial correlations with age, gender, and duration of disease as covariates were also calculated. Very weak correlations (absolute value of $r \leq 0.19$ ) were left out of the manuscript.
Acromegaly patients and matched controls Data analyses for the matched case-control design were stratified according to the control of acromegaly: patients with controlled disease and their matched controls, or patients with active disease and their matched controls. For each group of interest, categorical data are presented as percentages and continuous data as mean \pm s.D. or the median and IQR in case of nonnormal distribution. Matched groups were compared using conditional logistic regression (unadjusted analyses) with log-transformed continuous variables. Data analyses were performed using IBM SPSS Statistics Version 20.0 Software (IBM Corporation).

\section{Results}

\section{Acromegalic patients}

Clinical characteristics As shown in Table 1, patients with controlled and active acromegaly were of similar age, but the group with active disease had a significantly higher proportion of males. Patients with controlled disease had the longest duration of disease. Active acromegaly seemed to be associated with more diabetes and less ischemic heart disease, but the difference did not reach significance. No differences were found for smoking, percentage of macroadenomas,

Table 1 Baseline characteristics of the 200 patients with controlled $(n=105)$ vs active acromegaly $(n=95)$.

\begin{tabular}{|c|c|c|c|}
\hline Parameter & $\begin{array}{l}\text { Controlled } \\
\text { disease }(n=105)\end{array}$ & $\begin{array}{l}\text { Active } \\
\text { disease }(n=95)\end{array}$ & $P$ value ${ }^{*}$ \\
\hline Age (years), mean \pm S.D. & $53.6 \pm 12.7$ & $54.2 \pm 14.2$ & 0.828 \\
\hline Male gender (\%) & 41.0 & 62.1 & 0.003 \\
\hline \multicolumn{4}{|l|}{ Medical history } \\
\hline Active smoking (\%) & 22.5 & 25.3 & 0.736 \\
\hline Macroadenoma (\%) & 89.2 & 79.3 & 0.058 \\
\hline Duration of disease (years), median (IQR) & $11.0(7.0,17.0)$ & $8.0(4.0,13.0)$ & 0.050 \\
\hline Diabetes (\%) & 15.2 & 25.3 & 0.077 \\
\hline Hypertension (\%) & 37.9 & 37.2 & 0.927 \\
\hline Cerebrovascular disease (\%) & 3.8 & 3.2 & 0.470 \\
\hline Ischemic heart disease (\%) & 6.7 & 3.2 & 0.526 \\
\hline Cardiomyopathy (\%) & 8.6 & 5.3 & 0.801 \\
\hline \multicolumn{4}{|l|}{ Clinical parameters $^{\mathrm{a}}$} \\
\hline BMI $\left(\mathrm{kg} / \mathrm{m}^{2}\right)$, mean \pm s.D. & $29.0 \pm 5.3$ & $28.4 \pm 4.5$ & 0.475 \\
\hline Systolic BP $(\mathrm{mmHg})$, mean \pm s.D. & $128.2 \pm 17.0$ & $131.2 \pm 15.5$ & 0.348 \\
\hline Diastolic BP $(\mathrm{mmHg})$, mean \pm S.D. & $79.8 \pm 9.9$ & $82.0 \pm 10.0$ & 0.411 \\
\hline \multicolumn{4}{|l|}{ Therapy } \\
\hline Radiotherapy (\%) & 39.1 & 35.2 & 0.672 \\
\hline Surgery (\%) & 80.5 & 68.1 & 0.065 \\
\hline Dopamine agonist (\%) & 12.4 & 20.0 & 0.204 \\
\hline Somatostatin agonist (\%) & 42.9 & 60.0 & 0.023 \\
\hline Lipid-lowering drug (\%) & 14.3 & 10.5 & 0.522 \\
\hline \multicolumn{4}{|l|}{ Deficiencies } \\
\hline ACTH $(\%)$ & 28.6 & 13.6 & 0.016 \\
\hline TSH (\%) & 23.8 & 10.5 & 0.022 \\
\hline LH/FSH (\%) & 35.2 & 30.5 & 0.578 \\
\hline Vasopressin (\%) & 5.7 & 1.0 & 0.154 \\
\hline
\end{tabular}

${ }^{*} P$ values for $\chi^{2}$ or Fischer's exact test for categorical data, and Student's $t$-test based on log-transformed continuous data. IQR, interquartile range; $\mathrm{BP}$, blood pressure.

${ }^{a}$ Multivariable (regression) analysis adjusting for age, gender, and duration of disease based on log-transformed continuous data. 
presence of hypertension, cerebrovascular disease, and cardiomyopathy.

After adjustment for age, gender, and duration of disease, no difference was observed between both groups regarding BMI and blood pressure. Patients with active acromegaly underwent less neurosurgery and had more therapy with dopamine agonists and somatostatin analogs, only the latter reaching statistical difference. Patients with controlled disease suffered from more frequent pituitary deficits in ACTH and TSH.

Biochemical parameters By definition, levels of $\mathrm{GH}$ and IGF1 were significantly different between either groups (Table 2). No differences were found in lipid levels and in levels of adiponectin and sE-selectin. Concordant with the higher frequency of diabetes, significantly higher levels of fasting glucose, HbAlc, and insulin were seen in patients with active acromegaly.

Patients with active acromegaly had markedly lower levels of hs-CRP (2.5-fold), IL6 (1.5-fold), and NT-proBNP (1.5-fold) than patients with controlled disease (Fig. 1, Table 2). The observed differences for hs-CRP, IL6, and NT-proBNP were statistically significant after adjusting for age, gender, and duration of disease (Table 1, final column), and remained statistically significant even after further adjusting for the presence of TSH and ACTH deficiency and for the presence of diabetes, arterial hypertension, and cardiac disease $(P<0.001, P=0.001$, and $P=0.005$ for hs-CRP, IL6, and NT-proBNP respectively). According to the multivariable regression analyses, diabetes, arterial hypertension, and cardiac disease had no impact on differences in hs-CRP and IL6 (all $P$ values larger than 0.05). Interestingly, the presence of diabetes was associated with a smaller negative difference in NT-proBNP $(P=0.025)$, arterial hypertension had no impact on the differences in NT-proBNP $(P=0.481)$, and cardiac disease was associated with a positive difference in NT-proBNP $(P<0.001)$.

Correlations between hs-CRP and NT-proBNP and other cardiovascular risk markers Significant inverse correlations were found between IGF1 SDS and hs-CRP (Pearson's correlation coefficient $r=-0.408$, $P<0.001$; partial correlation with age, gender, and duration of disease as covariates $=-0.369$, $P<0.001)$, IL6 $(r=-0.284, P<0.001$; partial correlation $=-0.287, P<0.001)$. A strong positive relationship was found between hs-CRP and IL6 $(r=0.497$, $P<0.001$; partial correlation $=0.466, P<0.001)$.

hs-CRP correlated also positively with BMI $(r=0.288$, $P<0.001$; partial correlation $=0.289, P<0.001)$ and triglycerides $(r=0.304, P<0.001$; partial correlation $=-0.261, \quad P<0.001)$ and negatively with HDL-cholesterol $(r=-0.202, P<0.001$; partial correlation $=-0.214, P=0.002$ ). NT-proBNP showed a positive correlation with age $(r=0.477, P<0.001$; partial correlation $=0.372, P<0.001)$ and with adiponectin $(r=0.334, \quad P<0.001$; partial correlation $=0.256, \quad P<0.001)$. IGF1 SDS correlated positively with fasting glycemia $(r=0.308, P<0.001$; partial correlation $=0.297, P<0.001)$ and fasting insulin $(r=0.228, P=0.001$; partial correlation $=0.281, P<0.001)$.

Influence of previous and current treatment Higher levels of hs-CRP were observed after radiation therapy (median (IQR), $1.50(0.50,4.90)$ vs $0.60(0.20,0.50)$; $P=0.001)$. In contrast, hs-CRP and NT-proBNP levels were not influenced by other types of therapy, in particular the use of somatostatin analogs. Likewise, when separately analyzing the patients who were

Table 2 Biochemical parameters of the 200 patients with controlled $(n=105)$ vs active acromegaly $(n=95)$.

\begin{tabular}{|c|c|c|c|c|}
\hline Parameter & Controlled disease & Active disease & $\begin{array}{c}\text { Unadjusted } \\
P \text { value }^{\mathrm{a}}\end{array}$ & $\begin{array}{c}\text { Adjusted } \\
P \text { value }\end{array}$ \\
\hline $\mathrm{GH}(\mu \mathrm{g} / \mathrm{l})$, median (IQR) & $0.95(0.42,1.76)$ & $2.60(1.43,4.52)$ & $<0.001$ & $<0.001$ \\
\hline IGF1 (SDS), median (IQR) & $0.81(0.11,1.49)$ & $3.53(2.64,4.47)$ & $<0.001$ & $<0.001$ \\
\hline IGF1 $(\mu \mathrm{g} / \mathrm{l})$, median (IQR) & $161.9(128.2,217.2)$ & $391.7(291.4,602.1)$ & $<0.001$ & $<0.001$ \\
\hline Total cholesterol $(\mathrm{mmol} / \mathrm{l})$, mean \pm s.D. & $5.28 \pm 0.91$ & $5.28 \pm 0.10$ & 0.905 & 0.926 \\
\hline HDL-cholesterol $(\mathrm{mmol} / \mathrm{l})$, mean \pm s.D. & $1.56 \pm 0.55$ & $1.49 \pm 0.40$ & 0.485 & 0.578 \\
\hline Triglycerides $(\mathrm{mmol} / \mathrm{l})$, mean \pm s.D. & $1.37 \pm 0.66$ & $1.31 \pm 0.91$ & 0.272 & 0.771 \\
\hline Glycemia $(\mathrm{mmol} / \mathrm{l})$, mean + s.D. & $5.19+1.20$ & $5.80+1.65$ & 0.002 & 0.002 \\
\hline HbA1c (\%), mean \pm s.D. & $5.78 \pm 0.77$ & $5.99 \pm 0.78$ & 0.068 & 0.046 \\
\hline Insulin $(\mu \mathrm{U} / \mathrm{ml})$, median (IQR) & $5.70(3.30,9.18)$ & $7.00(4.70,10.00)$ & 0.005 & 0.001 \\
\hline Adiponectin $(\mu \mathrm{g} / \mathrm{l})$, median (IQR) & $5161(3449,7699)$ & $5188(3504,8875)$ & 0.697 & 0.831 \\
\hline sE-selectin $(\mu \mathrm{g} / \mathrm{I})$, median (IQR) & $37.1(24.2,59.3)$ & $32.4(22.5,50.4)$ & 0.373 & 0.401 \\
\hline IL6 (ng/l), median (IQR) & $2.34(1.29,4.09)$ & $1.44(0.87,2.92)$ & $<0.001$ & $<0.001$ \\
\hline hs-CRP (mg/l), median (IQR) & $1.30(0.50,4.10)$ & $0.50(0.10,0.90)$ & $<0.001$ & $<0.001$ \\
\hline NT-proBNP (ng/l), median (IQR) & $71.0(43.0,184.0)$ & $47.0(26.0,86.0)$ & $<0.001$ & $<0.001$ \\
\hline
\end{tabular}

IQR, interquartile range.

aStudent's $t$-test based on log-transformed continuous data.

${ }^{\mathrm{b}}$ Multivariable (regression) analysis adjusting for age, gender, and duration of disease based on log-transformed continuous data. 

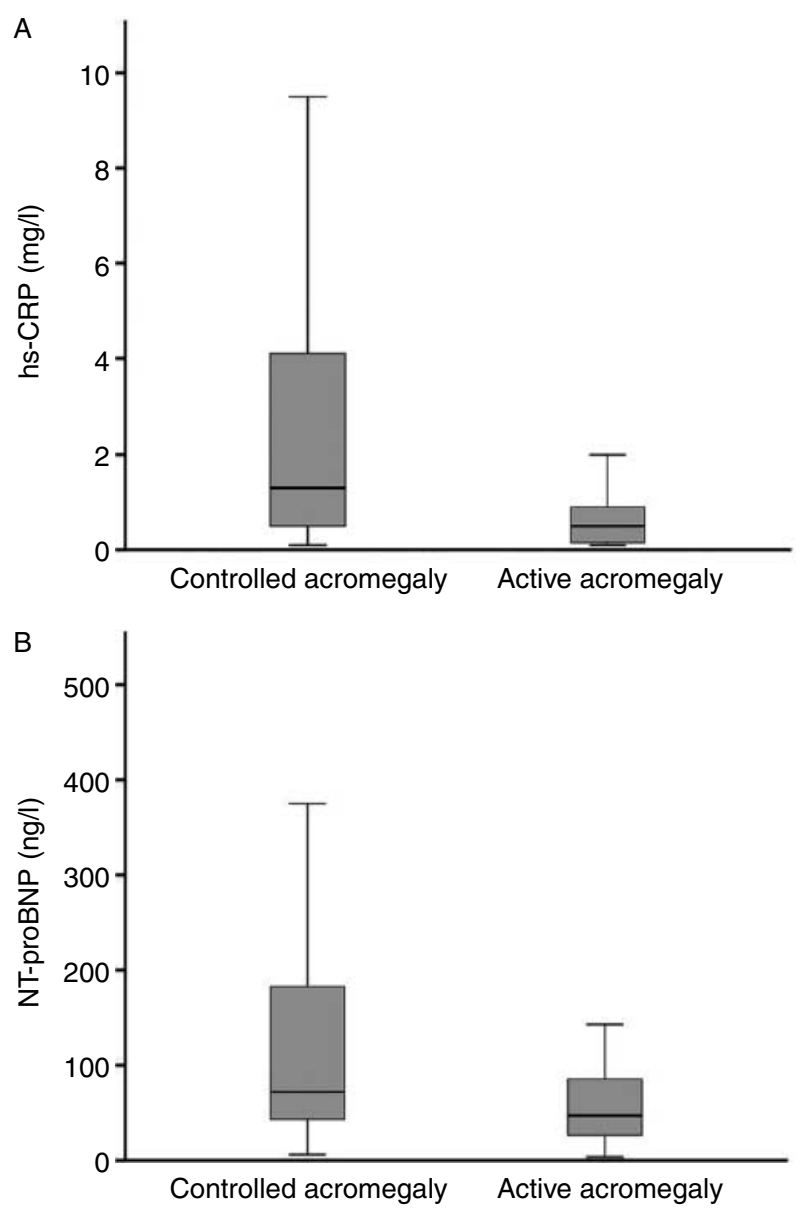

Figure 1 Boxplot for serum levels of hs-CRP (A) and NT-proBNP (B) in the 200 acromegalic patients with controlled $(n=105)$ vs active disease $(n=95)$. Student's $t$-test based on log-transformed continuous data: $P<0.001$ for both hs-CRP and NT-proBNP. Multivariable (regression) analysis adjusting for age, gender, and duration of disease based on log-transformed continuous data: $P<0.001$ for both hs-CRP and NT-proBNP.

strictly cured by surgery and those controlled by medical treatment, no statistically significant differences were found for hs-CRP, IL6, and NT-proBNP. Patients on somatostatin analogs had significantly higher levels of fasting glucose $(P<0.001)$ but comparable levels of insulin.

\section{Comparison with healthy controls matched for age, gender, and BMI}

The left panel of Table 3 shows the clinical and biochemical characteristics of the acromegalic patients with controlled disease $(n=84)$ and their matched controls $(n=167)$, while the right panel shows the clinical characteristics of the acromegalic patients with active disease $(n=65)$ and their matched controls $(n=130)$. In both categories, the prevalence of diabetes and fasting glycemia was higher among acromegaly patients than among matched controls. The prevalence of hypertension and diastolic blood pressure was higher in active acromegalics compared with matched controls, but not statistically different between patients with controlled disease and their matched controls.

Compared with the reference population, total cholesterol and triglycerides were lower in acromegaly whether the disease was controlled or not. In contrast, fasting glucose was higher in active disease patients compared with controls, but this was not the case for patients with a controlled disease.

The biomarkers for cardiovascular risk showed a different pattern. hs-CRP was markedly lower in active acromegaly than in controls, but similar between controlled patients and the reference subjects. NT-proBNP concentrations were higher in patients with controlled acromegaly compared with their matched group, and similar between active disease patients and controls. Finally, IL6 was significantly lower both in active and controlled acromegaly vs controls.

\section{Discussion}

Although patients with acromegaly are well known to suffer from increased cardiovascular morbidity, knowledge on cardiovascular risk factors in acromegaly is still inconclusive. Previous data have repeatedly shown that acromegaly is associated with an increased prevalence of hypertension and diabetes mellitus $(22,23)$. In this study, we were able to confirm in patients with active acromegaly a higher prevalence of diabetes and hypertension and higher levels of fasting glycemia and diastolic blood pressure. Conflicting data exist about the effect of acromegaly on lipid levels. Some studies indicate a worse lipid profile in active acromegaly $(9,24)$ while other authors reported better values $(22,25,26)$ and a worse profile after therapy (26). We found total cholesterol and triglycerides to be significantly lower both in controlled and non-controlled acromegaly.

In the current analysis, we focused predominantly upon two cardiovascular risk factors, hs-CRP and NT-proBNP, which have been shown in previous studies to deteriorate during acromegaly treatment. We could indeed document 2.5-fold lower hs-CRP levels and 1.5-fold lower NT-proBNP levels in a large group of patients with active acromegaly compared with patients with controlled disease. Levels of hs-CRP in active acromegaly were also much lower than those in the reference population, whereas NT-proBNP values were similar. In controlled acromegaly, hs-CRP was comparable to those of the normal population and NT-proBNP was higher.

This study thus confirms and extends previously reported data on cardiovascular risk factors in smaller groups of patients with acromegaly. This study is also more robust by the application of a large number of patients, the measurement of several other 
Table 3 Matched case-control design. Baseline and clinical characteristics of the patients with controlled acromegaly ( $n=84)$ and their matched controls $(n=167)$, and the patients with active disease $(n=65)$ and their matched controls $(n=130)$.

\begin{tabular}{|c|c|c|c|c|c|c|}
\hline Parameter & $\begin{array}{l}\text { Acromegaly } \\
\text { controlled } \\
\text { disease } \\
(n=84)\end{array}$ & $\begin{array}{l}\text { Matched } \\
\text { controls } \\
(n=167)^{\mathrm{a}}\end{array}$ & $P$ value ${ }^{\star}$ & $\begin{array}{l}\text { Acromegaly } \\
\text { active } \\
\text { disease } \\
(n=65)\end{array}$ & $\begin{array}{l}\text { Matched } \\
\text { controls } \\
(n=130)\end{array}$ & $P$ value ${ }^{\star}$ \\
\hline Age (years), mean \pm s.D. & $51.0 \pm 8.8$ & $51.1 \pm 8.9$ & NA & $50.3 \pm 8.8$ & $50.2 \pm 8.7$ & NA \\
\hline Males $(\%)$ & 41.7 & 41.9 & NA & 70.8 & 70.8 & NA \\
\hline Active smoking (\%) & 11.9 & 15.0 & 0.868 & 18.6 & 16.9 & 0.340 \\
\hline Arterial hypertension (\%) & 36.9 & 29.3 & 0.199 & 40.0 & 23.8 & 0.026 \\
\hline Diabetes mellitus (\%) & 13.1 & 4.8 & 0.020 & 21.5 & 6.9 & 0.006 \\
\hline BMI $\left(\mathrm{kg} / \mathrm{m}^{2}\right)$, mean \pm s.D. & $29.0 \pm 5.2$ & $28.8 \pm 5.0$ & NA & $28.8 \pm 4.2$ & $28.9 \pm 4.0$ & NA \\
\hline Systolic BP $(\mathrm{mmHg})$, mean \pm s.D. & $127.2 \pm 17.7$ & $130.1 \pm 14.2$ & 0.841 & $130.9 \pm 13.1$ & $130.5 \pm 13.0$ & 0.127 \\
\hline Diastolic BP $(\mathrm{mmHg})$, mean \pm s.D. & $79.6 \pm 10.1$ & $82.1 \pm 8.9$ & 0.469 & $82.9 \pm 9.1$ & $81.9 \pm 10.1$ & 0.025 \\
\hline Total cholesterol $(\mathrm{mmol} / \mathrm{l})$, mean \pm S.D. & $5.37 \pm 0.91$ & $5.80 \pm 0.91$ & 0.041 & $5.12 \pm 0.91$ & $5.40 \pm 0.98$ & $<0.001$ \\
\hline HDL-cholesterol (mmol/l), mean \pm s.D. & $1.58 \pm 0.56$ & $1.63 \pm 0.44$ & 0.654 & $1.46 \pm 0.41$ & $1.48 \pm 0.40$ & 0.186 \\
\hline Triglycerides $(\mathrm{mmol} / \mathrm{l})$, mean \pm S.D. & $1.36 \pm 0.70$ & $1.56 \pm 0.37$ & 0.001 & $1.25 \pm 0.58$ & $1.41 \pm 0.46$ & $<0.001$ \\
\hline Glycemia $(\mathrm{mmol} / \mathrm{l})$, mean $\pm \mathrm{s} . \mathrm{D}$. & $5.15 \pm 1.16$ & $5.25 \pm 0.75$ & 0.416 & $5.70 \pm 1.17$ & $5.31 \pm 0.81$ & 0.016 \\
\hline IL6 (ng/l), median (IQR) & $2.39(1.28,4.00)$ & $0.70(0.00,1.88)$ & 0.030 & $1.44(0.90,2.37)$ & $0.89(0.00,2.34)$ & 0.018 \\
\hline hs-CRP (mg/l), median (IQR) & $1.30(0.50,4.10)$ & $1.53(0.70,3.37)$ & 0.948 & $0.40(0.10,0.80)$ & $1.44(0.81,2.90)$ & $<0.001$ \\
\hline NT-proBNP (ng/l), median (IQR) & $66.5(40.0,119.5)$ & $50.8(26.5,79.7)$ & 0.001 & $43.0(24.5,64.5)$ & $31.6(18.9,65.8)$ & 0.478 \\
\hline
\end{tabular}

${ }^{\star} P$ value for conditional logistic regression analyzing the 1:2 matching by age, gender, and BMI. IQR, interquartile range; BP, blood pressure.

${ }^{a}$ One acromegaly patient (case) has only one matching control.

cardiovascular factors, the central determination of most assays, and the use of an age-, sex-, and BMImatched control group. Limitations of the study relate to the strategy of the study, using a cross-sectional instead of a longitudinal study design, and therefore the necessary use of surrogate endpoints for cardiovascular disease.

Regarding hs-CRP, our results are in accordance with those found in other studies on acromegaly $(12,15)$. The important role played by hs-CRP in the development of cardiovascular disease has been stressed in the general, non-acromegalic population. A strong association has indeed been demonstrated between elevated hs-CRP and an increased risk for coronary heart disease, ischemic stroke, and vascular mortality, even after correction for other risk factors (27). Whether hs-CRP is a nonspecific marker of the inflammation in atherosclerotic plaques or a direct participant in the progression of atherosclerosis remains an unsettled issue (28). Nevertheless, the present finding in acromegaly suggests less inflammation and a lower tendency to atheromatosis and this seems to be confirmed by clinical data $(6,7)$. It could therefore be speculated that a low hs-CRP level in active acromegaly counteracts the risk caused by other cardiovascular risk factors, such as hypertension and diabetes.

How GH/IGF1 exerts its effect on hs-CRP is still debated. This may be directly through the immune system (29) or through stimulation of secretion of endothelial adhesion molecules such as vascular cell adhesion molecule 1 , which can promote leukocyte extravasation (30). Another hypothesis relates to the effect of $\mathrm{GH}$ on visceral and central fat. As adipose tissue is a source of IL6 synthesis (31) and IL6 is an important regulator of CRP production (32), low hs-CRP levels in active acromegaly may be a reflection of a lower proportion of fat (12). In accordance with this hypothesis, a negative correlation was found between hs-CRP and BMI in this study. hs-CRP was also negatively related to HDL-cholesterol and positively related to triglyceride levels, two factors known to be highly influenced by visceral fat.

We also found lower concentrations of NT-proBNP in active acromegaly patients, similar to healthy controls, and higher than normal levels in controlled disease. This finding is in accordance with two studies which found lower levels of NT-proBNP in active acromegaly compared with controlled disease $(13,17)$, but do not confirm other studies which failed to find such differences $(16,18)$. BNP and its pro-hormone proBNP are secreted by the heart in response to volume overload and induce natriuresis. Plasma BNP and NT-proBNP levels, the latter being more specific, predict all-cause mortality and cardiovascular events including heart failure, myocardial infarction, stroke, atrial fibrillation, and cardiovascular death in stable patients with or without known cardiovascular disease and provide information about cardiovascular risk additional to that provided by traditional risk factors (11). Although in the general population low levels of NT-proBNP are considered advantageous for the heart, it is unclear if this is also applicable in acromegaly. An argument in favor of a beneficial effect is the finding of an increase in enddiastolic volume after 3 months of acromegaly therapy, accompanied by increased levels of BNP and NT-proBNP, thus suggesting an initial alteration of cardiac function after starting GH-lowering treatment (33).

However, a direct inhibition of BNP or NT-proBNP by $\mathrm{GH}$, independent of cardiac function, cannot be excluded. High levels of NT-proBNP are observed in 
patients with severe GH deficiency and are corrected by GH therapy $(13,34,35)$. However, in such conditions, the observed changes in these natriuretic peptides are not correlated with changes in cardiac structure or function $(35,36,37)$, thus suggesting that effects of $\mathrm{GH}$ are here independent of cardiovascular alterations. Alternatively, indirect effects of $\mathrm{GH}$ through its effects on kidney filtration and fluid equilibrium may also be considered. This would imply inappropriately low levels of BNP in situations of GH-induced volume overload, and in that case a rather unfavorable phenomenon (13). Clearly, more studies are needed to clarify this issue.

Adiponectin has anti-atherogenic and anti-inflammatory properties with direct effects on endothelial cells and macrophage-to-foam cell transformation. We and others $(38,39)$ failed to find any difference in levels of adiponectin between active acromegaly and controlled disease. These results support the view that adiponectin levels do not significantly improve during treatment of acromegaly. Contrasting to our findings, other authors did find a significant increase in adiponectin levels during acromegaly treatment, but the change was small $(40,41)$.

In conclusion, patients with active acromegaly have lower values of hs-CRP, and this might be linked to the relatively low incidence of coronary artery disease in these patients, despite the increase in other risk factors such as hypertension or diabetes. NT-proBNP is also lower in active acromegaly, but it remains unclear if this reflects a beneficial effect on the heart or not. Adequate treatment of acromegaly reverses these positive changes in cardiovascular risk factors, next to many well-known beneficial effects.

\section{Declaration of interest}

The authors declare that there is no conflict of interest that could be perceived as prejudicing the impartiality of the research reported.

\section{Funding}

This work was supported by a grant from Novartis Belgium through the Belgian Endocrine Society. M Bex was the recipient of a Clinical Doctoral Grant of the Research Foundation - Flanders (FWO).

\section{References}

1 Holdaway IM, Bolland MJ \& Gamble GD. A meta-analysis of the effect of lowering serum levels of GH and IGF-1 on mortality in acromegaly. European Journal of Endocrinology 2008159 89-95. (doi:10.1530/EJE-08-0267)

2 Dekkers OM, Biermasz NR, Pereira AM, Romijn JA \& Vandenbroucke JP. Mortality in acromegaly: a metaanalysis. Journal of Clinical Endocrinology and Metabolism 200893 61-67. (doi:10.1210/jc.2007-1191)

3 Sherlock M, Ayuk J, Tomlinson JW, Toogood AA, AragonAlonso A, Sheppard MC, Bates AS \& Stewart PM. Mortality in patients with pituitary disease. Endocrine Reviews 201031 301-342. (doi:10.1210/er.2009-0033)
4 Paisley AN, Banerjee M, Rezai M, Schofield RE, Balakrishnannair S, Herbert A, Lawrance JA, Trainer PJ \& Cruickshank JK. Changes in arterial stiffness but not carotid intimal thickness in acromegaly. Journal of Clinical Endocrinology and Metabolism 201196 1486-1492. (doi:10.1210/jc.20102225)

5 Colao A. The GH-IGF-I axis and the cardiovascular system: clinical implications. Clinical Endocrinology $200869347-358$. (doi:10.1111/j.1365-2265.2008.03292.x)

6 Bogazzi F, Battolla L, Spinelli C, Rossi G, Gavioli S, Di Bello V, Cosci C, Sardella C, Volterrani D, Talini E et al. Risk factors for development of coronary heart disease in patients with acromegaly: a five-year prospective study. Journal of Clinical Endocrinology and Metabolism 200792 4271-4277. (doi:10.1210/ jc. 2007-1213)

7 Akutsu H, Kreutzer J, Wasmeier G, Ropers D, Rost C, Möhlig M, Wallaschofski H, Buchfelder M \& Schöfl C. Acromegaly per se does not increase the risk for coronary artery disease. European Journal of Endocrinology 2010162 879-886. (doi:10.1530/EJE09-0945)

8 Otsuki M, Kasayama S, Yamamoto H, Saito H, Sumitani S, Kouhara H, Saitoh Y, Ohnishi T \& Arita N. Characterization of premature atherosclerosis of carotid arteries in acromegalic patients. Clinical Endocrinology 200154 791-796. (doi:10.1046/ j.1365-2265.2001.01281.x)

9 Boero L, Manavela M, Gómez Rosso L, Insua C, Berardi V, Fornari MC \& Brites F. Alterations in biomarkers of cardiovascular disease (CVD) in active acromegaly. Clinical Endocrinology 200970 88-95. (doi:10.1111/j.1365-2265.2008.03323.x)

10 Corrado E, Rizzo M, Coppola G, Fattouch K, Novo G, Marturana I, Ferrara F \& Novo S. An update on the role of markers of inflammation in atherosclerosis. Journal of Atherosclerosis and Thrombosis 201017 1-11. (doi:10.5551/jat.2600)

11 Campbell DJ. Can measurement of B-type natriuretic peptide levels improve cardiovascular disease prevention? Clinical and Experimental Pharmacology \& Physiology $2008 \quad 35$ 442-446. (doi:10.1111/j.1440-1681.2008.04894.x)

12 Sesmilo G, Fairfield WP, Katznelson L, Pulaski K, Freda PU, Bonert V, Dimaraki E, Stavrou S, Vance ML, Hayden D et al. Cardiovascular risk factors in acromegaly before and after normalization of serum IGF-I levels with the GH antagonist pegvisomant. Journal of Clinical Endocrinology and Metabolism 2002 87 1692-1699. (doi:10.1210/jc.87.4.1692)

13 Andreassen M, Faber J, Vestergaard H, Kistorp C \& Kristensen LØ. $\mathrm{N}$-terminal pro-B-type natriuretic peptide in patients with growth hormone disturbances. Clinical Endocrinology 200766 619-625. (doi:10.1111/j.1365-2265.2007.02782.x)

14 Delaroudis SP, Efstathiadou ZA, Koukoulis GN, Kita MD, Farmakiotis D, Dara OG, Goulis DG, Makedou A, Makris P, Slavakis A et al. Amelioration of cardiovascular risk factors with partial biochemical control of acromegaly. Clinical Endocrinology 200869 279-284. (doi:10.1111/j.1365-2265.2008.03181.x)

15 Kałuzny M, Bolanowski M, Daroszewski J \& Szuba A. The role of fibrinogen and CRP in cardiovascular risk in patients with acromegaly. Endokrynologia Polska 201061 83-88.

16 Potter BJ, Beauregard C \& Serri O. Serum markers of cardiovascular risk in patients with acromegaly before and after six months of treatment with octreotide LAR. Pituitary 200811 49-53. (doi:10.1007/s11102-007-0067-1)

17 Ito M, Kodama M, Tsumanuma I, Ramadan MM, Hirayama S, Kamimura T, Kashimura T, Fuse K, Hirono S, Okura Y et al. Relationship between insulin-like growth factor-I and brain natriuretic peptide in patients with acromegaly after surgery. Circulation Journal 200771 1955-1957. (doi:10.1253/circj.71. 1955)

18 Arikan S, Bahceci M, Tuzcu A \& Gokalp D. N-terminal pro-brain natriuretic peptide in newly diagnosed acromegaly. Journal of Endocrinological Investigation 201033 571-575.

19 Bex M, Abs R, T'Sjoen G, Mockel J, Velkeniers B, Muermans K \& Maiter D. AcroBel - the Belgian registry on acromegaly: a survey of 
the 'real-life' outcome in 418 acromegalic subjects. European Journal of Endocrinology 2007157 399-409. (doi:10.1530/EJE07-0358)

20 Rietzschel ER, De Buyzere ML, Bekaert S, Segers P, De Bacquer D, Cooman L, Van Damme P, Cassiman P, Langlois M, van Oostveldt P et al. Rationale, design, methods and baseline characteristics of the Asklepios Study. European Journal of Cardiovascular Prevention and Rehabilitation 200714 179-191. (doi:10.1097/HJR.0b013e32 $8012 \mathrm{c} 380$ )

21 Alexopoulou O, Bex M, Abs R, T’Sjoen G, Velkeniers B \& Maiter D. Divergence between growth hormone and insulin-like growth factor-I concentrations in the follow-up of acromegaly. Journal of Clinical Endocrinology and Metabolism $2008 \quad 93$ 1324-1330. (doi:10.1210/jc.2007-2104)

22 Berg C, Petersenn S, Lahner H, Herrmann BL, Buchfelder M, Droste M, Stalla GK, Strasburger CJ, Roggenbuck U, Lehmann N et al. Cardiovascular risk factors in patients with uncontrolled and long-term acromegaly: comparison with matched data from the general population and the effect of disease control. Journal of Clinical Endocrinology and Metabolism 201095 3648-3656. (doi:10.1210/jc.2009-2570)

23 Fieffe S, Morange I, Petrossians P, Chanson P, Rohmer V, Cortet C, Borson-Chazot F, Brue T \& Delemer B. Diabetes in acromegaly, prevalence, risk factors, and evolution: data from the French Acromegaly Registry. European Journal of Endocrinology 2011164 877-884. (doi:10.1530/EJE-10-1050)

24 Colao A, Pivonello R, Grasso LF, Auriemma RS, Galdiero M, Savastano S \& Lombardi G. Determinants of cardiac disease in newly diagnosed patients with acromegaly: results of a 10 year survey study. European Journal of Endocrinology $2011 \mathbf{1 6 5}$ 713-721. (doi:10.1530/EJE-11-0408)

25 Dimopoulou C, Sievers C, Wittchen HU, Pieper L, Klotsche J, Roemmler J, Schopohl J, Schneider HJ \& Stalla GK. Adverse anthropometric risk profile in biochemically controlled acromegalic patients: comparison with an age- and gender-matched primary care population. Pituitary $2010 \quad 13$ 207-214. (doi:10.1007/s11102-010-0218-7)

26 Parkinson C, Drake WM, Wieringa G, Yates AP, Besser GM \& Trainer PJ. Serum lipoprotein changes following IGF-I normalization using a growth hormone receptor antagonist in acromegaly. Clinical Endocrinology 200256 303-311. (doi:10.1046/ j.1365-2265.2002.01460.x)

27 Emerging Risk Factors Collaboration, Kaptoge S, Di Angelantonio E, Lowe G, Pepys MB, Thompson SG, Collins R \& Danesh J. C-reactive protein concentration and risk of coronary heart disease, stroke, and mortality: an individual participant meta-analysis. Lancet 2010 375 132-140. (doi:10.1016/S0140-6736(09)61717-7)

28 Scirica BM \& Morrow DA. Is C-reactive protein an innocent bystander or proatherogenic culprit? The verdict is still out Circulation $2006 \quad 113 \quad 2128-2134$ (discussion 2151). (doi:10.1161/CIRCULATIONAHA.105.611350)

29 van Buul-Offers SC \& Kooijman R. The role of growth hormone and insulin-like growth factors in the immune system. Cellular and Molecular Life Sciences $1998 \mathbf{5 4}$ 1083-1094. (doi:10.1007/ s000180050237)

30 Hansen TK, Fisker S, Dall R, Ledet T, Jorgensen JO \& Rasmussen LM. Growth hormone increases vascular cell adhesion molecule 1 expression: in vivo and in vitro evidence. Journal of Clinical Endocrinology and Metabolism $2004 \quad 89$ 909-916. (doi:10.1210/jc.2003-030223)

31 Mohamed-Ali V, Goodrick S, Rawesh A, Katz DR, Miles JM, Yudkin JS, Klein S \& Coppack SW. Subcutaneous adipose tissue releases interleukin- 6 , but not tumor necrosis factor- $\alpha$, in vivo. Journal of Clinical Endocrinology and Metabolism $1997 \mathbf{8 2}$ 4196-4200. (doi:10.1210/jc.82.12.4196)

32 Jakab L \& Kalabay L. The acute phase reaction syndrome: the acute phase reactants (a review). Acta Microbiologica et Immunologica Hungarica 199845 409-418.

33 Andreassen M, Faber J, Kjær A, Petersen CL \& Kristensen LØ. Cardiac effects of 3 months treatment of acromegaly evaluated by magnetic resonance imaging and B-type natriuretic peptides. Pituitary 201013 329-336. (doi:10.1007/s11102-010-0240-9)

34 Wallaschofski H, Saller B, Spilcke-Liss E, Lerch MM, Lohmann T \& Eigenthaler M. Effects of growth hormone treatment on B-type natriuretic peptide as a marker of heart failure in adults with growth hormone deficiency. Hormone and Metabolic Research 2006 38 656-661. (doi:10.1055/s-2006-954588)

35 Gruson D, Alexopoulou O, Pasquet A, Cumps J, Ketelslegers JM \& Maiter D. Impact of growth hormone $(\mathrm{GH})$ treatment on circulating NT-proBNP concentrations and on cardiac function in adult GH deficient patients. Scandinavian Journal of Clinical and Laboratory Investigation 201272 387-394. (doi:10.3109/ 00365513.2012.685887)

36 Lazurova I, Pura M, Wagnerova H, Tajtakova M, Sedlakova M, Tomas L, Payer J, Hruzikova P, Vanuga P, Podoba J et al. Effect of growth hormone replacement therapy on plasma brain natriuretic peptide concentration, cardiac morphology and function in adults with growth hormone deficiency. Experimental and Clinical Endocrinology \& Diabetes 2010118 172-176. (doi:10.1055/ s-0029-1220688)

37 Andreassen M, Faber J, Kjaer A, Petersen CL \& Kristensen LO. Cardiac function in growth hormone deficient patients before and after 1 year with replacement therapy: a magnetic resonance imaging study. Pituitary $2011 \mathbf{1 4}$ 1-10. (doi:10.1007/s11102010-0250-7)

38 Ronchi CL, Corbetta S, Cappiello V, Morpurgo PS, Giavoli C, BeckPeccoz P, Arosio M \& Spada A. Circulating adiponectin levels and cardiovascular risk factors in acromegalic patients. European Journal of Endocrinology 2004150 663-669. (doi:10.1530/eje. $0.1500663)$

39 Ueland T, Fougner SL, Godang K, Lekva T, Schurgers LJ, Scholz H, Halvorsen B, Schreiner T, Aukrust P \& Bollerslev J. Associations between body composition, circulating interleukin-1 receptor antagonist, osteocalcin, and insulin metabolism in active acromegaly. Journal of Clinical Endocrinology and Metabolism 201095 361-368. (doi:10.1210/jc.2009-0422)

40 Wiesli P, Bernays R, Brändle M, Zwimpfer C, Seiler H, Zapf J, A Spinas G \& Schmid C. Effect of pituitary surgery in patients with acromegaly on adiponectin serum concentrations and alanine aminotransferase activity. Clinica Chimica Acta 2005 352 175-181. (doi:10.1016/j.cccn.2004.09.022)

41 Sucunza N, Barahona MJ, Resmini E, Fernández-Real JM, Ricart W, Farrerons J, Rodríguez Espinosa J, Marin AM, Puig T \& Webb SM. A link between bone mineral density and serum adiponectin and visfatin levels in acromegaly. Journal of Clinical Endocrinology and Metabolism 200994 3889-3896. (doi:10.1210/jc.2009-0474)

Received 31 August 2012

Revised version received 2 November 2012

Accepted 6 November 2012 